\title{
Role of the phosphocreatine system on energetic homeostasis in skeletal and cardiac muscles
}

\author{
Papel do sistema da fosfocreatina na homeostase energética das \\ musculaturas esquelética e cardíaca
}

Lucas Guimarães-Ferreira ${ }^{1}$

\begin{abstract}
Adenosine triphosphate is the present energy currency in the body, and is used in various cellular and indispensable processes for the maintenance of cell homeostasis. The regeneration mechanisms of adenosine triphosphate, from the product of its hydrolysis adenosine diphosphate - are therefore necessary. Phosphocreatine is known as its quickest form of regeneration, by means of the enzyme creatine kinase. Thus, the primary function of this system is to act as a temporal energy buffer. Nevertheless, over the years, several other functions were attributed to phosphocreatine. This occurs as various isoforms of creatine kinase isoforms have been identified with a distinct subcellular location and functionally coupled with the sites that generate and use energy, in the mitochondria and cytosol, respectively. The present study discussed the central and complex role that the phosphocreatine system performs in energy homeostasis in muscle cells, as well as its alterations in pathological conditions.
\end{abstract}

Keywords: Phosphocreatine; Homeostasis; Muscle cells; Cardiac myocytes

\section{RESUMO}

A adenosina trifosfato é a moeda corrente de energia no organismo, sendo utilizada em diversos processos celulares e indispensável para a manutenção da homeostase celular. Mecanismos de regeneração da adenosina trifosfato, a partir de seu produto de hidrólise - a adenosina difosfato - são, dessa forma, necessários. A fosfocreatina é conhecidamente sua fonte mais rápida de regeneração, por meio da enzima creatina quinase. Assim, a principal função desse sistema é atuar como um tampão temporal de energia. Entretanto, ao longo dos anos, diversas outras funções foram atribuídas à fosfocreatina. Isso ocorreu à medida que foram identificadas diversas isoformas da creatina quinase com localização subcelular distinta e acopladas de forma funcional aos sítios geradores e utilizadores de energia, na mitocôndria e citosol, respectivamente. 0 presente trabalho discutiu o papel central e complexo que o sistema da fosfocreatina desempenha na homeostase energética nas células musculares, bem como suas alterações em quadros patológicos.

Descritores: Fosfocreatina; Homeostase; Células musculares; Miócitos cardíacos

\section{INTRODUCTION}

Adenosine triphosphate (ATP) is the primary source of chemical energy, and its hydrolysis is highly exergonic. Maintenance of cell homeostasis depends on mechanisms that adjust the ATP generation processes according to the demand for energy. Thus, the function of cell bioenergetics systems requires that the ATP produced and sent to the sites of use - the ATPases - be finely coupled with the removal of products of its hydrolysis - adenosine diphosphate (ADP), $\mathrm{Pi}$ and $\mathrm{H}^{+}-$so as to avoid the inhibition of ATPases, allowing continuity of biological processes.

Phosphocreatine (PCr) was discovered in 1927 in muscle tissue. Free creatinine $(\mathrm{Cr})$ was generated from its breakdown during muscle contraction. ${ }^{(1,2)}$ In 1962 , Cain and Davies inhibited the enzyme responsible for transforming $\mathrm{PCr}$ into $\mathrm{Cr}$ - creatine kinase (CK), and noted that the levels of ATP were rapidly reduced to the point that muscle contractions could no longer occur. ${ }^{(3)}$ Today it is clear that the PCr system is fundamental in promoting rapid resynthesis of ATP, by means of CK action (Equation 1).

$\mathrm{MgADP}+\mathrm{PCr}^{2-}+\mathrm{H}^{+} \Leftrightarrow \mathrm{MgATP}^{2-}+\mathrm{Cr}$ (Equation 1)

Since the PCr/CK system has a high level of ATP generation, it is particularly important in situations of

Universidade Federal do Espírito Santo, Vitoria, ES, Brazil.

Corresponding author: Lucas Guimarães-Ferreira - Avenida Fernando Ferrari, 514 - Goiabeiras - Zip code: 29075-810 - Vitória, ES, Brazil- Phone: (55 27) 4009-7882 - E-mail: lucas@cefd.ufes.br Received on: May 26, 2013 - Accepted on: Dec 12, 2013

DOI: 10.1590/\$1679-45082014RB2741 
high metabolic demand, such as high-intensity physical exercise, when the rate of ATP use exceeds its capacity for generation by other metabolic pathways.

\section{The phosphocreatine "shuttle" system}

In 1970, Gudbjarnason et al. noted that in skeletal muscle submitted to ischemia, contractile activity was interrupted when PCr was depleted, despite the levels of ATP being reduced by only about 20\%.(4) The authors suggested that intracellular ATP may not be homogeneously distributed in muscle cells or be capable of rapid and efficient diffusion.

Four different isoforms of CK were located with distinct subcellular locations: cytosolic isoforms CK-M and CK-B (from muscle and brain, due to the tissue in which they were first identified) and two mitochondrial isoforms (sarcomeric CKmit, found in muscles, and ubiquitous CKmit, in the rest of the tissues). In vivo, the cytosolic isoforms combine into dimers, forming CK-BB, CK-MB, and CK-MM; the latter is predominant in skeletal muscle. ${ }^{(5)}$ These findings, added to the first experiments demonstrating that the supply with $\mathrm{Cr}$ stimulated mitochondrial respiration, showed that the mitochondrial and cytoplasmic compartments were interconnected by an organized energy transfer system constituted by different isoforms of CK. Thus, the foundations for the so-called PCr "shuttle" theory were established, formally proposed by Bessman in 1972.(6)

In the PCr "shuttle" system (Figure 1), high-energy phosphate is transferred from the ATP formed by means of oxidative phosphorylation in the mitochondria (production site) to $\mathrm{Cr}$, via action of the CKmit, thus generating PCr and ADP. PCr diffuses into the cytoplasm, where under the action of cytosolic isoforms of CK, it generates ATP and Cr. ATP is then used by

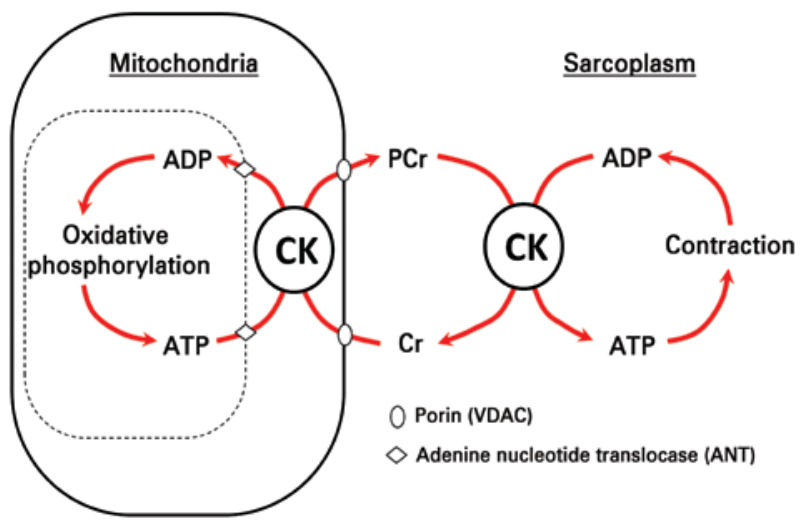

ADP: adenosine diphosphate; CK: creatinine kinase; PCr: phosphocreatine; ATP: adenosine triphosphate; Cr: free creatinine Figure 1. Phosphocreatine "shuttle" system

Adapted from: Neubauer $\mathrm{S}$. Influence of left ventricular pressures and heart rate on myocardial high-energy phosphate metabolism. Basic Res Cardiol. 1998;93 Suppl 1:102-7. Review. the ATPases (locations of use), while Cr returns to the interior of the mitochondria. This more easily crosses the mitochondrial membrane than the nucleotides of adenine, besides being present at higher levels in the intracellular medium. By means of this "shuttle" system, PCr performs another important function: it participates in the transfer of high-energy phosphate, present in ATP, from mitochondria to cytosol. ${ }^{(7,8)}$

The primary chemical reactions that use ATP in the skeletal and heart muscle are associated with the excitation-contraction coupling: myosin ATPase, in the microfibrils, and $\mathrm{Ca}^{2+}$-ATPase, in the sarcoplasmic reticulum (SR). Additionally, a major part of ATP is hydrolyzed by $\mathrm{Na}^{+} / \mathrm{K}^{+}$- ATPase in the sarcolemma. It has been demonstrated that CK is located in these sites, coupled, in a functional manner, to the ATPases. ${ }^{\left({ }^{8}\right.}$ Therefore, it is clear that the location of the CL isoforms is fundamentally important for the system to work in an adequate manner, i.e., for the ATP produced in the mitochondria to be effectively used by the cytosolic ATPases.

\section{Functional coupling system function for cell energy homeostasis}

As was discussed, data point to the existence of limiting factors for the free diffusion of ATP in the cytoplasm. Today we know that the first barrier to molecule diffusion in the intracellular medium is macromolecular agglomeration, which refers to the high concentrations of macromolecules in the interior of cells. The concentration of proteins in the cytoplasm is about 200 to $300 \mathrm{mg} / \mathrm{mL}$, which corresponds to 20 to $30 \%$ of the intracellular volume. ${ }^{(9,10)}$ In the mitochondria, this density is even higher, with mitochondrial proteins occupying about $60 \%$ of the matrix volume. ${ }^{(11)}$ This high viscosity medium may cause a decrease in volume available for free diffusion of substrates, ${ }^{(12)}$ thus determining the activity of many cell processes. ${ }^{(13)}$ This is why the results of enzymatic studies that use solutions diluted with isolated enzymes (cell-free systems) may not correspond to the intact condition of the cell.

Another barrier to the mobility of metabolites in the cell microenvironment is the bonding of these molecules. ${ }^{(14)}$ Szent-Györgyi and Prior ${ }^{(15)}$ demonstrated that most of the ADP remains firmly connected to units of actin of the cytoskeleton of the cell, showing, once again, the importance of the phosphate transfer network, since cytosolic ADP cannot move to the mitochondria in which it exerts control over the mitochondrial respiration rate. This problem is overcome by the functional coupling system accomplished by the PCr "shuttle". 
$\mathrm{Cr}$ and $\mathrm{PCr}$ are smaller molecules, with a small negative charge or none at all when compared to adenine nucleotides. Experiments with magnetic nuclear resonance demonstrated that the mean distance of diffusion (indicator of the capacity of molecule diffusion) of $\mathrm{PCr}$ and $\mathrm{Cr}(57$ and $37 \mu \mathrm{m})$ is much higher than that of ADP and ATP (1.8 and $22 \mu \mathrm{m}$, respectively). ${ }^{(16)}$ It is clear that among these metabolites, ADP is the limiting one as to the potential for diffusion through cytosol. Wallimann et al. reported that this potential, despite being low, is still sufficient to maintain the metabolic capacity in small cells or when the distance between the mitochondria and the cytosolic ATPases is not high, which does not match the properties of skeletal and cardiac muscles, making the energy transfer system through CK significant in these cells. ${ }^{(8)}$

While the agglomeration of macromolecules seems to be the primary mechanism of mobility restriction of larger solutes, bonding may be the most important mechanism in the case of smaller solutes. ${ }^{(14)}$ Since the production site of ATP in oxidative metabolism is in the interior of the mitochondria, and the locations of use are in the cytosol, the overlapping mechanisms of the barriers imposed by the low diffusion coefficients of adenine nucleotides and by the small availability of free ADP are essential. Obstacles coming from macromolecular bonding and agglomeration may be surpassed thanks to a mechanism of fine control and regulation of the metabolism, based on microcompartmentation and functional coupling. ${ }^{(10)}$

The spatial organization system, which allows interaction of enzymes, transporters, and their substrates in a supramolecular manner, is called functional coupling. This system is determined by two mechanisms that act in synergy in the accumulation and transfer of metabolites in small intercellular spaces, conferring greater efficiency to metabolic processes: metabolic canalization and cellular microcompartmentation.

By definition, compartment is a subcellular region in which biochemical reactions are kinetically isolated from each other. ${ }^{(17)}$ Inside the cells, the metabolism depends on the structural organization of the enzymes, forming microcompartments. Since the cells contain distinct microenvironments, the measurement of metabolite concentration in the whole cells or in certain tissues gives us an idea of the mean cell concentration, but not of the concentration of the metabolite under study which is effectively available at the active site of a particular enzyme. Therefore, cellular compartmentation may provide an additional control mechanism for metabolic pathways.

On the other hand, by means of metabolic canalization, an intermediate is transferred between adjacent enzymes, and depends less on cytosol diffusion. For example, it has been noted that the mean concentration of oxaloacetate in the mitochondrial matrix is much lower than necessary to support the function of the Krebs cycle. However, the high concentration of oxaloacetate, in the same microenvironment in which citrate synthase is located, allows the maintenance of speed of this cycle. ${ }^{(13)}$ This illustrates the importance of metabolic canalization and how cellular metabolism depends on the structural organization of the enzymes and intermediates, forming microcompartments.

In the $\mathrm{PCr} / \mathrm{CK}$ system, the functional coupling performs so that the different isoforms of $\mathrm{CK}$ can act in two distinct directions. While CKmit acts in the direction of $\mathrm{PCr}$ synthesis, the cytosolic isoforms of $\mathrm{CK}$ act in the direction of local formation of ATP, around the ATPases. This was first demonstrated by mathematical calculations $^{(18)}$ and then confirmed experimentally by means of magnetic resonance techniques with radioactive phosphorus. ${ }^{(19)}$

\section{Implications of changes in the phosphocreatine/creatinine kinase system}

Some studies demonstrated that compromise of the $\mathrm{PCr} / \mathrm{CK}$ system is related to a few functional alterations, especially in the myocardium. For example, transgenic mice that do not express guanidinoacetate$\mathrm{N}$-methyltransferase (GAMT), an enzyme necessary for synthesis of $\mathrm{Cr}$, showed a reduced inotropic reserve and increased susceptibility of lesion by ischemia/reperfusion due to deficiency of $\mathrm{Cr}$ and $\mathrm{PCr} .{ }^{(20)}$ Additionally, the myocardium of knock-out mice for the CKmit and CK-M isoforms is incapable of maintaining the levels of ATP when the animals are submitted to an intense exercise protocol, despite the baseline levels not showing modification. Also, these mice exhibit a significantly reduced free energy value $(\Delta G)$ for ATP hydrolysis during effort. ${ }^{(21)}$ This demonstrates that, in these animals, for which the total activity of CK is almost null, the increase in load imposed on the myocardium makes it more costly to generate work, reducing the free energy available with the hydrolysis of ATP. However, recent studies have raised questions as to the importance of the $\mathrm{PCr} / \mathrm{CK}$ system in the myocardium at rest or during light to moderate intensity exercise. For example, Lygate et al. ${ }^{(22)}$ demonstrated that knock-out mice for GAMT showed no decline in voluntary locomotor activity and in capacity for exercise until exhaustion when compared to control animals, despite the deficiency of $\mathrm{Cr}$. Furthermore, Branovets et al., ${ }^{(23)}$ using cardiomyocytes of animals with GAMT deficiency, concluded that PCr is not essential for cardiac function at rest. It is possible 
that the deficiency in $\mathrm{PCr}$ may cause contractile damage only in supramaximal exercise, but additional research is necessary to elucidate this issue.

It was also demonstrated that pathological conditions that lead to cardiac hypertrophy, in man and in animal models, are characterized by a decrease in concentrations of $\mathrm{Cr}$ and PCr. ${ }^{(24-29)}$ In humans, a study demonstrated that the magnitude of the decrease of this content is directly related to the degree of insufficiency observed. ${ }^{(26)}$ Thus, compromise of the PCr system seems to precede the development of the contractile dysfunction, leading to the reduction of energy reserves available for regeneration of ATP and making the myocardium more likely to develop insufficiency. ${ }^{(30)}$

The mechanisms that result in the decrease of $\mathrm{PCr}$ concentration include lower expression of the $\mathrm{Cr}$ transporter ${ }^{(27)}$ and modifications in the pattern of expression of the CK isoforms, which lead to the reduction of the total levels of $\mathrm{Cr}$ and of the $\mathrm{PCr} / \mathrm{Cr}$ ratio. ${ }^{(21)}$ Corroborating these findings, Ye et al., ${ }^{(31)}$ using a model of congestive heart insufficiency in pigs, observed a decrease in the PCr/ATP ratio and in the flow through $\mathrm{CK}$ with a significant reduction in the expression of CK-M and CKmit. These and other studies demonstrate that the damage of the $\mathrm{PCr} / \mathrm{CK}$ system seems to precede the development of the contractile dysfunction, leading to decreased energy reserve. ${ }^{(32)}$ The superexpression of the $\mathrm{Cr}$ transporter resulted in a moderate increase in the levels of $\mathrm{Cr}$ and glycogen, and protected the myocardium of the animals from acute infarction of the myocardium, with a $27 \%$ reduction in tissue necrosis, besides improved functional recovery after damage due to ischemia/reperfusion. ${ }^{(33)}$ Similarly, superexpression of the myofibril isoform of CK (CK-M) resulted in increase in ATP flow by CK and in improved contractile function in a model of cardiac insufficiency. ${ }^{(34)}$

Animals supplemented with $\beta$ guanidyl-propionic acid ( $\beta$-GPA, a competitor for Cr transport), which, however, show a significant depletion of $\mathrm{Cr}$ in the myocardium, also exhibit damage in cardiac function, especially with high workloads. In animals treated with $\beta$-GPA, increased concentration of free ADP makes $\Delta \mathrm{G}$ for ATP hydrolysis less negative, rendering this reaction less efficient in terms of energy. ${ }^{(32)}$ Since the sequester of calcium depends on a highly negative $\Delta \mathrm{G}$, and that $\mathrm{CK}$ is in the sarcoplasmic reticulum functionally coupled with SR, the drop in levels of $\mathrm{Cr}$ in the myocardium seems to explain part of the cardiac alterations observed in individuals and animals that present with decreased reserve of $\mathrm{Cr}$ under pathological or experimental conditions.

This is the case of hyperthyroidism, in which there is an accentuated drop in the supplies of $\mathrm{Cr}^{\left({ }^{(35)} \mathrm{It}\right.}$ is known that, under these conditions, the heart shows a limitation in maximal work capacity, with an accentuated reduction in the levels of ATP as the energy demand increases. ${ }^{(36,37)}$ Maybe the decrease in offer of $\mathrm{Cr}$ to the myocardium is responsible for this limitation. It was demonstrated that at low and high rates of work imposed on the heart (measured by systolic peak pressure versus heart rate), the myocardium of hyperthyroid animals shows decreased levels of ATP and elevated levels of free $\mathrm{ADP}^{(35)}$, which suggests that the excess of thyroid hormones has affected the heart's working capacity, in part due to the decreased supply of $\mathrm{Cr}$ in the myocardium, parallel to the accentuated drop in expression of the Cr transporter. A study with hypophysectomized rats demonstrated that the thyroid hormone promotes an increase in the levels of $\mathrm{PCr}$ and in the $\mathrm{PCr} / \mathrm{Cr}$ ratio in skeletal muscle, besides accelerating $\mathrm{PCr}$ regeneration after muscle contractions. ${ }^{(38)}$

On the other hand, in induction of the hypothyroid condition in rats for 3 weeks, Athéa et al. ${ }^{(39)}$ verified that it did not affect total CK activity, as well as the gene expression and activity of CKmit. However, the mitochondria of these animals showed a decrease in sensitivity to ADP and to $\mathrm{Cr}$, evidenced by the constant increase of the Michaelis-Menten constant $\left(\mathrm{Km}_{\mathrm{ADP}}\right.$ of $189 \pm 12 \mu \mathrm{M}$ to $228 \pm 12 \mu \mathrm{M}$ and $\mathrm{Km}_{\mathrm{ADP}+\mathrm{Cr}}$ of $65 \pm 5 \mu \mathrm{M}$ to $101 \pm 8 \mu \mathrm{M})$. In physiological terms, this means that more $\mathrm{ADP}$ and $\mathrm{Cr}$ are necessary under this experimental condition for the stimulation of the mitochondrial function. This effect may have occurred by the decrease of content of cardiolipin in the mitochondrial membrane, in which synthesis is stimulated by thyroid hormones. ${ }^{(40)}$ This phospholipids is important for the bond between CKmit and the mitochondrial membrane.(41) In this way, it is presumed that under conditions of hypothyroidism, the PCr "shuttle" system acts at a slower rhythm than under euthyroid conditions, ${ }^{(22)}$ which results in the lower availability of the ATP generated in the mitochondria for the locations of use in the cytoplasm. Khushu et al. ${ }^{(42)}$ demonstrated that despite the fact that patients with hypothyroidism display intramuscular levels of $\mathrm{PCr}$ similar to those of euthyroid individuals, the resynthesis of $\mathrm{PCr}$, after exercise, is reduced, indicating a reduction in oxidative capacity in the skeletal muscle.

A recent study in our group demonstrated that supplementation with $\mathrm{Cr}$ promotes the reduction of reactive oxygen species (ROS) in skeletal muscle. ${ }^{(43)}$ The increase in ROS production occurs in various metabolic, neurologic, and endocrine diseases, among others, and treatment with $\mathrm{Cr}$ has proved to be an efficient strategy in a large part of these diseases. ${ }^{(44)}$ Additional research should determine the true therapeutic potential of $\mathrm{Cr}$ supplementation. 


\section{CONCLUSION}

The understanding of the functional coupling phenomenon, involving cellular microcompartmentation and metabolic canalization, may help to better comprehend the integration among the various cellular systems of adenosine triphosphate generation that interact to maintain skeletal and cardiac cell homeostasis. In this regard we show that the regulation of cellular energy metabolism is intimately related to the organizational structure of the cell components. Such evidence brings to light part of the function, many times ignored, of the phosphocreatine/ creatinine kinase system, which contributes towards a better understanding of muscle physiology as well as relevant clinical aspects. Additionally, they point to relevant issues that still deserve more investigation in the field of cellular bioenergy.

\section{REFERENCES}

1. Fiske $\mathrm{CH}$, Subbarow $\mathrm{Y}$. The nature of the "inorganic phosphate" in voluntary muscle. Science. 1927;65(1686):401-3.

2. Eggleton P, Eggleton GP. The Inorganic Phosphate and a Labile Form of Organic Phosphate in the Gastrocnemius of the Frog. Biochem J. 1927;21(1):190-5.

3. Cain DF, Davies RE. Breakdown of adenosine triphosphate during a single contraction of working muscle. Biochem Biophys Res Commun. 1962;8:361-6.

4. Gudbjarnason S, Mathes P, Ravens KG. Functional compartmentation of ATP and creatine phosphate in heart muscle. J Mol Cell Cardiol. 1970;1 (3):325-39.

5. Jacobs $H$, Heldt HW, Klingenberg M. High activity of creatine kinase in mitochondria from muscle and brain and evidence for a separate mitochondrial isoenzyme of creatine kinase. Biochem Biophys Res Commun. 1964;16(6):516-21.

6. Bessman SP. Hexokinase acceptor theory of insulin action. New evidence. Isr J Med Sci. 1972;8(3):344-52.

7. Bessman SP, Geiger PJ. Transport of energy in muscle: the phosphorylcreatine shuttle. Science. 1981;211(4481):448-52. Review.

8. Wallimann T, Wyss M, Brdiczka D, Nicolay K, Eppenberger HM. Intracellular compartmentation, structure and function of creatine kinase isoenzymes in tissues with high and fluctuating energy demands: the 'phosphocreatine circuit' for cellular energy homeostasis. Biochem J. 1992;281 (Pt 1):21-40. Review.

9. Ellis RJ. Macromolecular crowding: an important but neglected aspect of the intracellular environment. Curr Opin Struct Biol. 2001;11(1):114-9. Review.

10. Saks V, Beraud N, Wallimann T. Metabolic compartmentation - a system level property of muscle cells: real problems of diffusion in living cells. Int $\mathrm{J}$ Mol Sci. 2008;9(5):751-67.

11. Scalettar BA, Abney JR, Hackenbrock CR. Dynamics, structure, and function are coupled in the mitochondrial matrix. Proc Natl Acad Sci USA. 1991;88(18):8057-61.

12. Fulton AB. How crowded is the cytoplasm? Cell. 1982;30(2):345-7. Review.

13. Ovádi J, Saks V. On the origin of intracellular compartmentation and organized metabolic systems. Mol Cell Biochem. 2004;256-257(1-2):5-12. Review.

14. Verkman AS. Solute and macromolecule diffusion in cellular aqueous compartments. Trends Biochem Sci. 2002;27(1):27-33. Review.

15. Szent-Györgyi AG, Prior G. Exchange of adenosine diphosphate bound to actin in superprecipitated actomyosin and contracted myofibrils. J Mol Biol. 1966;15(2):515-38.

16. Yoshizaki K, Watari H, Radda GK. Role of phosphocreatine in energy transport in skeletal muscle of bullfrog studied by 31P-NMR. Biochim Biophys Acta. 1990;1051(2):144-50.

17. Papadopuloulos S, Jürgens KD, Gros G. Protein diffusion in living skeletal muscle fibers: dependence on protein size, fiber type, and contraction. Biophys J. 2000;79(4):2084-94.

18. Saks VA, Chernousova GB, Gukovsky DE, Smirnov VN, Chazov El. Studies of energy transport in heart cells. Mitochondrial isoenzyme of creatine phosphokinase: kinetic properties and regulatory action of $\mathrm{Mg} 2+$ ions. Eur J Biochem. 1975;57(1):273-90

19. Joubert F, Mazet JL, Mateo P, Hoerter JA. 31P NMR detection of subcellular creatine kinase fluxes in the perfused rat heart: contractility modifies energy transfer pathways. J Biol Chem. 2002;277(21):18469-76.

20. ten Hove M, Lygate CA, Fischer A, Schneider JE, Sang AE, Hulbert K, et al. Reduced inotropic reserve and increased susceptibility to cardiac ischemia/reperfusion injury in phosphocreatine-deficient guanidinoacetateN-methyltransferase-knockout mice. Circulation. 2005;111(19):2477-85.

21. Saupe KW, Spindler M, Hopkins JC, Shen W, Ingwall JS. Kinetic, thermodynamic, and developmental consequences of deleting creatine kinase isoenzymes from the heart. Reaction kinetics of the creatine kinase isoenzymes in the intact heart. J Biol Chem. 2000;275(26):19742-6.

22. Lygate CA, Aksentijevic D, Dawson D, ten Hove M, Phillips D, de Bono JP, et al. Living without creatine: unchanged exercise capacity and response to chronic myocardial infarction in creatine-deficient mice. Circ Res. 2013;112(6):945-55.

23. Branovets J, Sepp M, Kotlyarova S, Jepihhina N, Sokolova N, Aksentijevic D, et al. Unchanged mitochondrial organization and compartmentation of highenergy phosphates in creatine-deficient GAMT-/- mouse heart. Am J Physiol Heart Circ Physiol. 2013;305(4):H506-20.

24. Seppet EK, Adoyaan AJ, Kallikorm AP, Chernousova GB, Lyulina NV, Sharov $V G$, et al. Hormone regulation of cardiac energy metabolism. I. Creatine transport across cell membranes of euthyroid and hyperthyroid rat heart Biochem Med. 1985;34(3):267-79.

25. Tian R, Ingwall JS. The molecular energetics of the failing heart from animal models-small animal models. Heart Failure Rev. 1999;4:235-53.

26. Zhang J, Bache RJ. The molecular energetics of the failing heart from animal models-large animal models. Heart Failure Rev. 1999;3(4):255-67.

27. Neubauer S, Remkes H, Spindler M, Horn M, Wiesmann F, Prestle J, et al. Downregulation of the $\mathrm{Na}(+)$-creatine cotransporter in failing human myocardium and in experimental heart failure. Circulation. 1999;100(18):1847-50.

28. Nakae I, Mitsunami K, Omura T, Yabe T, Tsutamoto T, Matsuo S, et al. Proton magnetic resonance spectroscopy can detect creatine dpletion associated with the progression of heart failure in cardiomyopathy. J Am Coll Cardiol. 2003;42(9):1587-93.

29. Nakae I, Mitsunami K, Matsuo S, Horie M. Creatine depletion and altered fatty acid metabolism in diseased human hearts: clinical investigation using $1 \mathrm{H}$ magnetic resonance spectroscopy and 123I BMIPP myocardial scintigraphy. Acta Radiol. 2007;48(4):436-43.

30. Horn M, Remkes H, Strömer H, Dienesch C, Neubauer S. Chronic phosphocreatine depletion by the creatine analogue beta-guanidinopropionate is associated with increased mortality and loss of ATP in rats after myocardial infarction. Circulation. 2001;104(15):1844-9.

31. Ye Y, Gong G, Ochiai K, Liu J, Zhang J. High-energy phosphate metabolism and creatine kinase in failing hearts: a new porcine model. Circulation. 2001;103(11):1570-6.

32. Ingwall JS, Weiss RG. Is the failing heart energy starved? On using chemical energy to support cardiac function. Circ Res. 2004;95(2):135-45. Review.

33. Lygate CA, Bohl S, ten Hove M, Faller KM, Ostrowski PJ, Zervou S, et al. Moderate elevation of intracellular creatine by targeting the creatine transporter protects mice from acute myocardial infarction. Cardiovasc Res. 2012;96(3):466-75.

34. Gupta A, Akki A, Wang Y, Leppo MK, Chacko VP, Foster DB, et al. Creatine kinase-mediated improvement of function in failing mouse hearts provides causal evidence the failing heart is energy starved. J Clin Invest. 2012:122(1):291-302. 
35. Queiroz MS, Shao Y, Berkich DA, Lanoue KF, Ismail-Beigi F. Thyroid hormone regulation of cardiac bioenergetics: role of intracellular creatine. Am J Physiol Heart Circ Physiol. 2002;283(6):H2527-33.

36. Brent GA. The molecular basis of thyroid hormone action. N Engl J Med. 1994;331(13):847-53. Review.

37. Polikar R, Burger AG, Scherrer U, Nicod P. The thyroid and the heart. Circulation. 1993;87(5):1435-41. Review.

38. Kaminsky P, Walker PM, Deibener J, Barbe F, Jeannesson E, Escanye JM, et al. Growth hormone potentiates thyroid hormone effects on post-exercise phosphocreatine recovery in skeletal muscle. Growth Horm IGF Res. 2012;22(6):240-4.

39. Athéa Y, Garnier A, Fortin D, Bahi L, Veksler V, Ventura-Clapier R. Mitochondrial and energetic cardiac phenotype in hypothyroid rat. Relevance to heart failure. Pflugers Arch. 2007;455(3):431-42.

40. Mutter T, Dolinsky VW, Ma BJ, Taylor WA, Hatch GM. Thyroxine regulation of monolysocardiolipin acyltransferase activity in rat heart. Biochem J. 2000;346 Pt 2:403-6.

41. Schlattner U, Wallimann T. Octamers of mitochondrial creatine kinase isoenzymes differ in stability and membrane binding. J Biol Chem. 2000;275(23):17314-20.

42. Khushu S, Rana P, Sekhri T, Sripathy G, Tripathi RP. Bio-energetic impairment in human calf muscle in thyroid disorders: a 31P MRS study. Magn Reson Imaging. 2010;28(5):683-9.

43. Guimarães-Ferreira L, Pinheiro CH, Gerlinger-Romero F, Vitzel KF, Nachbar RT, Curi $R$, et al. Short-term creatine supplementation decreases reactive oxygen species content with no changes in expression and activity of antioxidant enzymes in skeletal muscle. Eur J Appl Physiol. 2012;112(11):3905-11.

44. Sestili P, Martinelli C, Colombo E, Barbieri E, Potenza L, Sartini S, et al. Creatine as an antioxidant. Amino Acids. 2011;40(5):1385-96. 